\title{
6-Gingerol and Shogaol; A Comprehensive Strategy Against Various Maladies
}

\section{ISSN: 2637-8078}

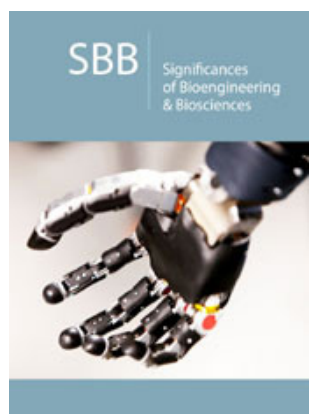

For HTML Version scan this QR code:

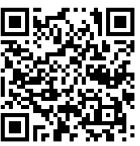

*1Corresponding author: Muhammad Hanif Mughal, Homeopathic Clinic, Islamabad, Pakistan

Submission: 留 February 25, 2019

Published: 眥 March 12, 2019

Volume 3 - Issue 1

How to cite this article: Muhammad Hanif Mugha.6-Gingerol and Shogaol; A Comprehensive Strategy Against Various Maladies. Significances Bioeng Biosci. 3(1).SBB.000551.2019.

DOI: 10.31031/SBB.2019.03.000551

Copyright@ Muhammad Hanif Mughal, This article is distributed under the terms of the Creative Commons Attribution 4.0 International License, which permits unrestricted use and redistribution provided that the original author and source are credited.

\author{
Muhammad Hanif Mughal* \\ Homeopathic Clinic, Pakistan
}

\begin{abstract}
Ginger is the oldest medical herb due to its therapeutic and prophylactic activities. These properties are associated with the presence of the gingerol and shogaol. The literature pertaining to current review article has been mainly emphasized on the therapeutic potential of ginger along with active bio-ingredients against cancer insurgence, diabetic \&oxidative stress complications, obesity and cardiovascular discrepancies. It prevents from cancer insurgence through restraining the cancer stages such as initial, promotion and progression. Particularly, it also suppresses the lipid per-oxidation, nitric oxide synthetase activity, epidermal growth factor (EGF) receptor, protein kinase c, enzyme activity, survival signaling (NIK, IKK, and AKT), NF-KB activity, and cell cycle regulation. The current review article discusses the role of gingerol bioactive component against different type of cancers and its allied health perspectives.
\end{abstract}

Keywords: Ginger; Gingerol; Anticancer; Antidiabetic; Cardiovascular Role

\section{Introduction}

Ginger (Zingiber officinale Roscoe) has been used as delicacy, medicine, and in variety of food from many years [1]. It is traditional oriental herbal medicine and promotes numerous health endorsing effects due to the presence of bioactive compounds. It is also used to enhance the flavor of the vegetables during cooking [2]. Ginger is a promising source of bioactive moieties i.e. gingerols, shogaols, parasols, and zingerone and used to curtail various diseases including cancer, oxidative stress, diabetes, obesity, overweight, microbial contamination and aging etc. [3]. Regarding photochemistry of oils of ginger, they include volatiles and nonvolatiles as sesquiterpene, monoterpenoid and gingerols, shogaols, parasols, and zingerone, respectively. A group of researchers Schweiggert et al. [4] \& Hu et al.[5] quantified the oleoresin and its major components have been recognized as [6]-, [8]-, and [10]-shogaols and [4]-,[6]-, [8]-, [10]-, and [12]-gingerols by high performance liquid chromatography mass spectrometry [4,5]. Baliga et al. [6] also reported the biological and pharmacological activities of ginger bioactive compounds such as gingerols and shogaols have varying alkyl side chain lengths [6]. During thermal treatment, gingerols are labile due to the presence of b-hydroxy keto moiety and further dehydrated to shogaols. Both compounds have an unbranched alkyl chain of six carbon atoms and similar in structure [7]

\section{Antioxidant status}

The ethanolic extracts of gingerol were more effective than aqueous extracts and showed higher free radical scavenging activities and chelating abilities. It also inhibited the production of superoxide in human promyelocytic leukemia (HL-60) cells due to the presence of hydroxyl group in its structure [8]. [6]-Gingerol also suppressed peroxynitrite-induced oxidative singlestrand DNA breaks and protein nitrosylation. The antioxidant potential of gingerol is affected by multiple factors such as concentration, localization, and mobility [9]. The previous findings of Masuda et al. [10] reported that gingerol also suppressed the phospholipid peroxidation induced by the FeCl3-ascorbate system and also exhibited the inhibitory effect on xanthine oxidase system which are linked with the production of ROS. Likewise, gingerol $(0.5-10 \mu \mathrm{M})$ also inhibited the formation of thromboxane $\mathrm{B}_{2}$ and prostaglandin $\mathrm{D}_{2}$ and arachidonic acid induced platelet aggregation in dose dependent manner [11]. Similarly, Shobana \& Naidu 
[12] reported that water and alcoholic extracts of ginger possessed potent antioxidant activity and prevented from lipid peroxidation. Furthermore, gingerol also suppresses the reactive oxygen species (ROS) and protected from DNA damage that associated with coronary heart disease, and carcinogenesis.

\section{Oxidative stress}

It is the imbalance between production of free radicals and antioxidants. Different doses of gingerol at the rate of 20, 200, and $75 \mathrm{mg} / \mathrm{kg}$ lowered the malondialdehyde, and enhanced the antioxidant enzymes such as glutathione peroxidase, and catalase [13]. 6-gingerol has effective role against mercuric chlorideinduced oxidative stress in male male sprague-dawley rats. The supplementation of gingerol $(50 \mathrm{mg} / \mathrm{kg})$ prevented from the enhancement in level of lipid peroxides, creatinine, alkaline phosphatase, urea, uric acid, lactate dehydrogenase, transaminases, and decline in concentrations of antioxidant enzymes catalase, superoxide dismutase, glutathione peroxidase, glutathione reductase, and glutathione-S-transferase [14]. Multiple mechanisms are involved by gingerol against oxidative stress such as (i) reduction in levels of malondialdehyde, (ii) tumor necrosis factor- $\alpha$, (iii) nitric oxide, (iv) apoptotic (caspase-3) markers as well as also improvement in concentrations of catalase, glutathione peroxidase, superoxide dismutase, and glutathione S-transferase as well as glutathione level in the brain of rat [15]. The oral supplementation of gingerol at the rate of 50,100 and $200 \mathrm{mg} / \mathrm{kg}$ markedly protected from CBZ-mediated enhancement in the organo-somatic index of the testes and seminiferous tubular diameter in the rats. Likewise, 6-gingerol ameliorated CBZ-induced disruption in the epithelium height as well as in the proportion of tubule and interstitial of the epididymis the treated rats. Furthermore, 6-gingerol prevented CBZ-mediated increase in testicular acid phosphatase activity and the decrease in testicular alkaline phosphatase, aminotransferases, glucose-6-phosphate dehydrogenase and lactate dehydrogenase activities. Moreover, 6-gingerol ameliorated CBZ-induced reduction in the testicular and epididymal sperm count and sperm motility in the treated rats [16]. Gingerol in gentamicin-induced renal cortical oxidative stress in adult male albino rats significantly decreased the renal function tests, tubular dilatation with marked vacuolar degeneration and desquamation of cells, interstitial hemorrhage and cellular infiltration [17]. Furthermore, gingerol has been found effectual agent against oxidative stress complications in the livers and kidneys of rats through increasing the levels of catalase, superoxide dismutase, glutathione S-transferase, glutathione peroxidase as well as glutathione. It also significantly prevented from the elevation in malondialdehyde and hydrogen peroxide $\left(\mathrm{H}_{2} \mathrm{O}_{2}\right)$ livers and kidneys as well as also protected from the increment in hepatic dysfunction and plasma indices of renal [16].

\section{Anti-obesity role}

Obesity is associated with high accumulation of fat in the body and an imbalance between energy intake and expenditure. It is also characterized by altered lipid metabolic processes, including lipogenesis and lipolysis. There are many anti-obesity drugs which have adverse effects on the body along with reducing body weight. Ginger is prominent source of bioactive compound including volatile oil and non-volatile pungent compounds i.e. gingerols, shogaols and zingerones [18]. Gingerol also significantly lowers the body weight due to its hypophagic property in the high-fat diet-induced adiposity. It also shows anti-obesity action via inhibiting intestinal absorption of dietary fat and prevents from the cardiovascular diseases [19].

\section{Anti-cancer role}

6-gingerol suppresses the transformation, hyper-proliferation, and inflammatory processes which are linked with the development of carcinogenesis, angiogenesis and metastasis. It is also inducing apoptosis in the prostate cancer cell line $\mathrm{LnCaP}$ via enhancing the expression of p53 and $\mathrm{Ba}$ and lowering the expression of Bcl-2. [6]-Gingerol inhibited invasion and metastasis through multiple molecular mechanisms in hepatocellular carcinoma [20,21]. Cyclin D1 is a protooncogene and associated with cell proliferation via activation by $\beta$ catenin signaling. Nonsteroidal anti-inflammatory drugs (NSAID) are used to activate the gene1 (NAG1) that promote the proapoptotic and antitumorigenic properties. By performing anticancer activity, gingerol show apoptotic effect in cancer cells through stimulating and inducing apoptosis, up regulating NAG1 and G1 cell cycle arrest, and down regulating cyclin D1. Leukotrienes induce the forcefully inflammatory response to develop cancer [22]. [6]-Gingerol directly binds with LTA4H and inhibits LTA4H enzyme activity in HCT116 and HT29 cells [23]. Similarly, Lee et al. [24] observed significant reduction in growth of HCT-116 cells treated with different concentrations of 6 -gingerol $(0,50,100,150$, and $200 \mathrm{mM}$ ). The $150-$ and $200-\mathrm{mM}$ concentrations of 6-gingerol lowered the cell growth rate by $22 \%$ and $28 \%$, respectively in HT29 cells, HCT-116, Caco- 2 cells, and LoVo, respectively.

Gingerol supplementation suppressed colon carcinogenesis by reducing lipid peroxidation and significantly enhancing the enzymatic and non-enzymatic anti-oxidant levels [25]. [6]-gingerol also suppressed the gastric lesions induced by $\mathrm{HCl}$ and ethanol in rats. In experimental animals, it also inhibits the proliferation of mouse skin carcinogenesis and exhibits inhibitory effect on tumor initiation and promotion owing to its presence of pungent vanillyl ketones [8]. The earlier investigations of Park et al. [26] explicated that [6]-gingerol also suppressed the TPA skin tumor proliferated activity and inhibited the epidermal ornithine decarboxylase activity. A study conducted by Surh et al. [8], they investigated that [6]-gingerol attenuated the skin papilloma genesis induced by 7,12-dimethylbenz [a]anthracene (DMBA). It has multiple mechanisms for the prevention of cancer via inhibiting the tumorpromoter-stimulated inflammation, suppressing the activation of epidermal ornithine decarboxylase, and inhibiting TNF-alpha production [27]. In mouse skin tumorigenesis model, ethanolic extract of bioactive compound gingerol exhibited anti-tumor activity in animals by substantially lowering tumor body burdens as compared to control rats. The mouse skin was treated with gingerol extract and significantly inhibited the TPA that cause reduction in 
hyperplasia (44\%) and epidermal edema (56\%) [27]. In another study done by Kim et al. [28], they determined that [6]-gingerol treatment suppressed the TPA-induced COX-2 expression along with inhibited NF- jB DNA binding activity [28]. Moreover, it also lowered the incidence and the multiplicity of tumors initiated by DMBA and promoted by TPA. It also suppressed $\mathrm{H}_{2} \mathrm{O}_{2}$ production, myeloperoxidase activity and inhibited the TPA-induced ear edema in the dorsal skin of mice [29]. Likewise, Murakami et al. [30] evaluated the anti-tumor role of gingerol in mouse skin via conventional 2-stage carcinogenesis model. It prevented from the tumor initiation and promotion through inducing apoptosis, metabolizing enzymes and attenuating pro-inflammatory signaling pathways. One study conducted by Shukla et al. [25], administration of gingerol (2lM) for 24h markedly inhibited the average number of tumors by $80 \%$ and skin tumor incidence by $60 \%$.

It shows inhibitory effect on tumor proliferation and promotion owing to its pungent vanillyl ketones [8, 25]. It also suppressed the TPA skin tumor promotion and epidermal ornithine decarboxylase activity in ICR mice [2]. Gingerol exerts anticancer mechanism against skin papilloma genesis in female ICR which is induced by 7,12-dimethylbenz[a]anthracene (DMBA) through inhibition of the tumor-promoter-stimulated inflammation, suppression of TNF-alpha production, and inhibition of activation of epidermal ornithine decarboxylase. Likewise, ethanolic extracts of gingerol inhibits the TPA mediated induction of ornithine decarboxylase and its mRNA expression in SENCAR mouse skin. It also lowers the tumor body burdens compared with non-ginger treated controls. Gingerol significantly inhibits the TPA caused epidermal edema (56\%) and hyperplasia (44\%). Similarly, in UVB-induced skin cancer, gingerol also protects from the production of ultra violet B (UVB)-induced ROS and COX-2 expression [27]. In mouse skin cancer cells, gingerol performs the cytotoxic effect by lowering the multiplicity of azoxymethane-induced intestinal carcinogenesis and reduces the incidence of DMBA-initiated papilloma formation. It also momentously suppressed the tumor promoter-induced inflammation [26]. Gingerol $(10 \mu \mathrm{M})$ has cytotoxic effect on breast cancer cells through inhibiting metastasis by decreasing the activities and expressions of MMP-2 and MMP-9 [24].

In one study conducted by Rahman et al. [31] investigated the anticancer role og gingerol extract against human breast carcinoma cell lines MCF-7 and highly invasive MDA-MB-231 cancer cells. They determined that ginger extract $(25.7 \mu \mathrm{g} / \mathrm{ml})$ showed the higher anticancer activity on MCF-7 cancer cells and MDAMB-231. Likewise, Hong et al. [32] reported that concentrations (75 and $100 \mu \mathrm{M})$ of 6-shogaol or pterostilbene have modulatory effects on aggressive breast cancer cells MDA-MB-231 cells. They lowered the migration of the MDA-MB-231 cells up to 22 and $41 \%$, respectively. They also lowered the activities of MMP-2 and MMP9 expressions. In PMA-treated HepG2 and PMA-untreated Hep3B cells, gingerol has anti-invasive activity via regulating MMP-9 and TIMP-1, and 6-shogaol could further regulate uPA activity [20]. Yagihashi et al. [33] also determined the antiinvasive activity of 6-Gingerol by suppressing the ROS-potential in AH109A cells. It also neutralizes the formation of free radicals such as superoxide, peroxyl, peroxynittrite and further suppresses the formation of peroxy nitrite-mediated tyrosine nitration and production of nitric oxide [34]. It also reduces the generation of iNOS in LPS-stimulated J774.1 cell [35].

In BXPC-3 cells (mutant p53 protein) and HPAC cells (wild type p53), gingerol suppresses the cell growth, disrupts the cell cycle progression, and induces apoptosis. It also lowers the Cyclin A and Cdks expressions i.e. Cdk2, Cdk4, \& Cdk6 whilst cyclin A and Cdk 6 expressions were lowered in HPAC. The blocking of CyclinCdk complexes formation significantly lowered the Cyclin or Cdk expressions that further reduced phospho- Rb level. On other side, in BXPC-3 cells, the levels of Cyclin D1 enhanced due to the druginduced cell cycle arrestp53 and gene encoding a transcription factor. It also suppresses the cell proliferation in cells through cell cycle arrest and/or inducing apoptosis [36].

It induces apoptosis via up regulating NAG-1 and G1cell cycle arrest through down regulating cyclin D1. Gingerol significantly inhibits the growth of Helicobacter pylori Cag $\mathrm{A}^{+}$strains that are responsible for gastric premalignant and malignant lesions. It also suppresses the pulmonary metastasis in mice bearing B16F10 melanoma cells by activating $\mathrm{CD}^{8+} \mathrm{T}$ cells [37]. By performing antitumoral activity, it also causes the induction of ROS that triggers the activation of p53 and the cell cycle arrest and apoptosis [38].

\section{Anti-diabetic Role}

Type 2 diabetes are significantly increasing worldwide and associated with insulin resistance and pancreatic b-cell failure. During hyperglycemia, endogenous non enzymatic reactions produce the advanced glycation end products (AGEs) and enhance the concentration of pancreatic b-cell. Gingerol provides protection to pancreatic b-cells from free radicals-induced stress as well also has effect on blood sugar level, glucose intolerance and gene expression of hepatic enzymes. [6]-Gingerol stimulated the phosphorylation of AMPK to total AMPK, and p-AMPK/AMPK from $30 \mathrm{~min}$ after treatment and further lowered the production of free radicals of RIN-5F cells [39].

It also suppressed the production of IL-1 $\beta$, TNF- $\alpha$, and IL-12 from LPS-stimulated macrophages [40]. Gingerol also inhibits the MAPK and PI3K/Ak phosphorylation and NF- $\mathrm{KB}$ and STAT3 translocation [41]. Likewise, it also acts as anti-hyperglycemic by improving the insulin signaling pathway. It stimulated the glucose uptake that lowered the expressions of AMPK, acetyl-CoA carboxylase (ACC), and phosphorylation in L6 myotubes rats [42]. In diabetes, oxidative stress enhances the production of free radicals whereas gingerol stops the effects of ROS and lowers the lipid level in type 2 diabetes models ( $\mathrm{db} / \mathrm{db}$ mice). Gingerol enhanced the anti-oxidant enzyme activities and decreased hydrogen peroxide concentration in $\mathrm{db} / \mathrm{db}$ mice. It also lowers the hepatic and renal MDA levels $\mathrm{db} /$ $\mathrm{db}$ mice. In diabetic animals, gingerol has potential to enhance the insulin sensitivity and to decrease hyperlipidemia [43].

\section{Cardio preventive Role}

[6]-gingerol enhanced the viability of doxorubicin-injured cardiomyocytes. It also has more profound protective effects than 
single agent drug. The drug lowered the SOD activity, enhanced ROS generation, increased MDA formation, triggered the intrinsic mitochondria-dependent apoptotic pathway, and induced release of LDH in cardiomyocytes. Gingerol exerts cardioprotective effect against doxorubicin-induced cardiotoxicity through activating the PI3K/Akt signaling pathway [44].

6-gingerol significantly ameliorated the doxorubicin-induced elevation in the cardiac enzymes. The stimulation of oxidative stress by doxorubicin was evidenced by the significant decrease in the serum soluble receptor for advanced glycation product allowing unopposed serum advanced glycation end product availability. Moreover, doxorubicin activated nuclear factor kappa B (NF- $\kappa$ B) which was indicated by an increase in its immunohistochemical staining in the nucleus. In addition, doxorubicin-induced cardiotoxicity was accompanied by elevation of cardiac caspase-3. Notably, pretreatment with 6-gingerol significantly ameliorated the changes in sRAGE, NF- $\mathrm{BB}$ and cardiac caspase-3. Cardiac enzymes showed significant positive correlation with NF- $\kappa B$ and caspase- 3 but negative with serum sRAGE, suggesting their role in doxorubicin-induced cardiac injury [45]. The previous findings of Antipenko et al. [46] determined that the concentration of gingerol (50 micro) enhanced the Vmax (Ca) of $\mathrm{Ca}^{2+}$ uptake and $\mathrm{Ca}^{2+}$-ATPase activity as well also increased the $\mathrm{Km}(\mathrm{Ca})$ in phosphorylated vesicles.

\section{Conclusion}

Ginger is used traditionally in worldwide for its health endorsing properties such as reducing cardiovascular disease, cancer, diabetes, allergic response, aging and cancer. It exhibits the beneficial effects due to the presence of gingerol and shogaol. They target multiple pathways, inclusive of the cell cycle, apoptotic cell death and angiogenic pathway, which confer their anticarcinogenic activities. These polyphenols prevent from the gastric cancer, lung cancer, bone cancer, pulmonary cancer, uterine cancer, esophageal cancer, colon cancer, liver cancer and breast cancer. The current review article summarized that gingerol consumption was associated with a statistically significant 9\% decreased risk of gastric cancer and reduced the risk against colorectal and gastric cancers. The active form of gingerol can be stabilized into biocompatible materials such as alginate beads and layered double hydroxides. This review encompasses the multiple health effects of gingerol with references to health perspectives.

\section{References}

1. Poltronieri J, Becceneri AB, Fuzer AM, Filho JCC, et al. (2014) [6]-gingerol as a cancer chemo preventive agent: a review of its activity on different steps of the metastatic process. Mini-Rev Med Chem 14(4): 313-321.

2. Park EJ, Pizzuto JM (2002) Botanicals in cancer chemoprevention. Cancer Metast Rev 21(3-4): 231-255.

3. Ghasemzadeh A, Jaafar HZE, Rahmat A (2010) Antioxidant activities, total phenolics and flavonoids content in two varieties of Malaysia young ginger (Zingiber officinale Roscoe). Molecules 15(6): 4324-4333.

4. Schweiggert U, Hofmann S, Reichel M, Schieber A, Carle R (2008) Enzymeassisted liquefaction of ginger rhizomes (zingiber officinale rosc.) for the production of spray-dried and paste-like ginger condiments. J Food Eng 84(1): 28-38
5. Hu J, Guo Z, Glasius M, Kristensen K, et al. (2011) Pressurized liquid extraction of ginger (Zingiber officinale Roscoe) with bioethanol: an efficient and sustainable approach. J Chromatogr A 1218(34): 57655773.

6. Baliga MS, Haniadka R, Pereira MM, D'souza JJ et al. (2011) Update on the chemo preventive effects of ginger and its phytochemicals. Crit Rev Food Sci Nutr 51(6): 499-523.

7. Jolad SD, Lantz RC, Chen GJ, Bates RB, Timmermann BN (2005) Commercially processed dry ginger (Zingiber officinale): composition and effects on LPS-stimulated PGE2 production. Phytochemistry 66(13): 1614-1635.

8. Surh YJ, Park KK, Chun KS, Lee LJ, et al. (1999) Anti-tumor-promoting activities of selected pungent phenolic substances present in ginger. J Environ Pathol Toxicol Oncol 18(2): 131-139.

9. Niki E, Noguchi $N$ (2004) Dynamics of antioxidant action of vitamin E. Accounts Chem Res 37(1): 45-51.

10. Masuda Y, Kikuzaki H, Hisamoto M, Nakatani N (2004) Antioxidant properties of gingerol related compounds from ginger. Biofactors 21(1): 293-296.

11. Guh JH, Ko FN, Jong TT, Teng CM (1995) Antiplatelet effect of gingerol isolated from Zingiber officinale. J Pharm Pharmacol 47(4): 329-332.

12. Shobana S, Naidu KA (2000) Antioxidant activity of selected Indian spices. Prostaglandins Leukotrienes and Essential Fatty Acids 62(2): 107-110.

13. Eid BG, Mosli H, Hasan A, El Bassossy HM (2017) Ginger ingredients alleviate diabetic prostatic complications: effect on oxidative stress and fibrosis. Evid Based Complement Alternat Med: 6090269.

14. Joshi D, Srivastav SK, Belemkar S, Dixit VA (2017) Zingiber officinale and 6-gingerol alleviate liver and kidney dysfunctions and oxidative stressinduced by mercuric chloride in male rats: A protective approach. Biomed Pharmacother 91: 645-655.

15. Abolaji A, Ojo M, Afolabi TT, Arowoogun MD, et al. (2017) Protective properties of 6-gingerol-rich fraction from Zingiber officinale (Ginger) on chlorpyrifos-induced oxidative damage and inflammation in the brain, ovary and uterus of rats. Chem Biol Interact 270: 15-23.

16. Salihu M, Ajayi BO, Adedara IA, Farombi EO (2016) 6-Gingerol-Rich Fraction from Zingiber officinale prevents hepatotoxicity and oxidative damage in kidney and liver of rats exposed to carbendazim. J Diet Suppl 13(4): 433-448.

17. Hegazy AM, Mosaed MM, Elshafey SH, Bayomy NA (2016) 6-gingerol ameliorates gentamicin induced renal cortex oxidative stress and apoptosis in adult male albino rats. Tissue Cell 48(3): 208-216

18. Taspell LC, Hampell I, Cobiac C (2006) Health benefits of herbs and spices. Med J Austria 185: 4-24.

19. John H, Beattie F, Margaret JG (2011) Ginger phytochemicals mitigate the obesogenic effects of a high-fat diet in mice: A proteomic and biomarker network analysis. Mol Nutr Food Res 55: S203-S213.

20. Weng CJ, Chou CP, Ho CT, Yen GC (2012) Molecular mechanism inhibiting human hepatocarcinomatous cell invasion by 6-shogaol and 6-gingerol. Mol Nutr Food Res 56(8): 1304-1314.

21. Nigam N, George J, Srivastava S, Roy P, Bhui K, et al. (2010) Induction of apoptosis by [6]-gingerol associated with the modulation of p53 and involvement of mitochondrial signaling pathway in B[a]P-induced mouse skin tumorigenesis. Cancer Chemother Pharmacol 65(2): 687696.

22. Gunning WT, Kramer PM, Steele VE, Pereira MA (2002) Chemoprevention by lipoxygenase and leukotriene pathway inhibitors of vinyl carbamateinduced lung tumors in mice. Cancer Res 62(13): 4199-4201.

23. Ghosh AK, (2011) International journal of pharma and bio sciences (Gingerol might be a sword to defeat colon cancer)? 
24. Lee HS, Seo EY, Kang NE, Kim WK (2008) [6]-Gingerol inhibits metastasis of MDA-MB-231 human breast cancer cells. J Nutr Biochem 19(5): 313319.

25. Shukla Y, Singh M (2007) Cancer preventive properties of ginger: a brief review. Food Chem Toxicol 45(5): 683-690.

26. Park KY, Chun KS, Lee JM, Lee SS (1998) Inhibitory effects of [6]-gingerol, a major pungent principle of ginger, on phorbol ester-induced inflammation, epidermal ornithine decarboxylase and skin tumor promotion in ICR mice. Cancer Lett 129(2): 139-144.

27. Katiyar SK, Agarwal R, Mukhtar H (1996) Inhibition of tumor promotion in SENCAR mouse skin by ethanol extract of Zingiber officinale rhizome. Cancer Res 56(5): 1023-1030.

28. Kim SO, Chun KS, Kundu JK, Surh YJ (2004) Inhibitory effects of [6]gingerol on PMA-induced COX-2 expression and activation of NF-KB and p38 MAPK in mouse skin. Bio factors 21(1-4): 27 -31.

29. Chung WY, Jung YJ, Surh YJ, Lee SS, Park KK (2001) Antioxidative and antitumor promoting effects of [6]-paradol and its homologs. Mutat Res 496(1-2): 199-206.

30. Murakami A, Tanaka T, Lee JY, Surh YJ, et al. (2004) Zerumbone, a sesquiterpene in subtropical ginger, suppresses skin tumor initiation and promotion stages in ICR mice. Int J Cancer 110 (4): 481 - 490.

31. Rahman S, Salehin F, Iqbal A (2011) In vitro antioxidant and anticancer activity of young Zingiber officinale against human breast carcinoma cell lines. BMC Complement Altern Med 11(76).

32. Hong $\mathrm{BH}, \mathrm{Wu} \mathrm{CH}$, Yeh $\mathrm{CT}$, Yen GC (2013) Invadopodia-associated proteins blockade as a novel mechanism for 6-shogaol and pterostilbene to reduce breast cancer cell motility and invasion. Molecular Nutrition and Food Research 57(5): 886-895.

33. Yagihashi S, Miura Y, Yagasaki K (2008) Inhibitory effect of gingerol on the proliferation and invasion of hepatoma cells in culture. Cytotechnology 57(2): 129-136.

34. Shin SG, Kim JY, Chung HY, Jeong JC (2005) Zingerone as an antioxidant against peroxy nitrite. J Agric Food Chem 53(19): 7617-7622.

35. Ippoushi K, Azuma K, Ito H, Horie H, Higashio H (2003) [6]-Gingerol inhibits nitric oxide synthesis in activated J774.1 mouse macrophage and prevents peroxynitrite-induced oxidation and nitration reactions. Life Sci 73(26): 3427-3437.
36. Willis AC, Chen X (2002) The promise and obstacle of p53 as a cancer therapeutic agent. Curr Mol Med 2(4): 329- 345.

37. Suzuki F, Kobayashi M, Komatsu Y, Kato A et al, (1997) Keishi-ka-kei-to, A traditional Chinese herbal medicine, inhibits pulmonary metastasis of B16 melanoma. Anticancer Res 17(2A): 873-878.

38. Karna P, Chagani S, Gundala SR, Rida P, et al. (2012) Benefits of whole ginger extract in prostate cancer. Br J Nutr 107(4): 473-484.

39. Son, MJ, Miura Y, Yagasaki K. (2014) Mechanisms for antidiabetic effect of gingerol in cultured cells and obese diabetic model mice. Cytotechnology 67(4): 641-652.

40. Tripathi S, Maier KG, Bruch D, Kittur DS (2007) Effect of 6-gingerol on pro-inflammatory cytokine production and costimulatory molecule expression in murine peritoneal macrophages. J Surg Res 138(2): 209213.

41. Weng CJ, Chou CP, Ho CT, Yen GC (2012) Molecular mechanism inhibiting human hepatic carcinoma cell invasion by 6-shogaol and 6-gingerol Molecular Nutrition \& Food Research 56: 1304-1314.

42. Chakraborty D, Mukherjee A, Sikdar S, Paul A, et al. (2012) [6]-Gingerol isolated from ginger attenuates sodium arsenate induced oxidative stress and plays a corrective role in improving insulin signaling in mice. Toxically Lett 210(1): 34-43.

43. Singh AB, Singh AN, Maurya R, Srivastava AK (2009) Anti-hyper glycemic, lipid lowering and anti-oxidant properties of [6]-gingerol in $\mathrm{db} / \mathrm{db}$ mice. International Journal of Medicine and Medical Sciences 1(12): 536-544.

44. Chen YL, Zhuang XD, Xu ZW, Lu LH, et al. (2013) Hienamine Combined with [6]-Gingerol Suppresses Doxorubicin-Triggered Oxidative Stress and Apoptosis in Cardiomyocytes via Upregulation of PI3K/Akt Pathway. Evid Based Complement Alternat Med: 970490.

45. El Bakly WM, Louka ML, El Halawany AM, Schaalan MF (2012) 6-gingerol ameliorated doxorubicin-induced cardiotoxicity: role of nuclear factor kappa B and protein glycation. Cancer Chemother Pharmacol 70(6): 833-841.

46. Antipenko AY, Spielman AI, Kirchberger MA (1999) Interactions of 6-gingerol and ellagic acid with the cardiac sarcoplasmic reticulum Ca2+-ATPase. J Pharmacol Exp Ther 290(1): 227-234. 